\title{
Educação em sexualidade de mães adolescentes institucionalizadas num centro de apoio à vida
}

\author{
Sónia PEREIRA ${ }^{1}$ \\ Teresa VILAÇA ${ }^{2}$
}

\section{Introdução}

A maternidade leva a adolescente a incorporar as exigências associadas à tarefa de ser mãe, passando a desempenhar um papel social que se prolonga no tempo e que encontra expressáo nas questóes das diferenças sexuais, influenciando a identidade social das mulheres (ABUCKAIM, 2005). A maternidade é assim extraordinária e/ou banal dependendo da predisposição biológica da adolescente para a procriação (MONTEIRO, 2005) e da influencia das representaçóes sociais da sociedade em que a mãe adolescente vive (ABUCKAIM, 2005; CANAVARRO, 2001; MONTEIRO, 2005; MOTA; MADEIRA, 2010). No contexto Português, ser mãe adolescente significa uma fuga à norma social e uma transgressão da regulação social da sexualidade ligada à idade adulta e ao estigma da mãe solteira (VILAR; GASPAR, 2005).

Ser mãe adolescente é um desafio marcado por sentimentos contraditórios com aquisições, dúvidas, ansiedades e frustrações, o que envolve uma grande carga emocional e stress, pois a mãe, como principal prestadora de cuidados,

1 Mestre em Intervenção Psicossocial com Crianças, Jovens e Famílias. UMinho Universidade do Minho. Braga - PO - Portugal. 4710-057- soniafcp@sapo.pt

2 UMinho - Universidade do Minho. Centro de Investigação em Educação. Braga PO - Portugal.4710-057-tvilaca@ie.uminho.pt 
sente-se obrigada a encontrar estratégias para articular os seus diferentes papéis sociais (mãe, jovem, estudante, filha, amiga, etc.), acedendo, simultaneamente, a uma identidade social valorizada (MONTEIRO, 2005). Ser mãe adolescente requer, assim, lidar com todas as transformaçóes físicas e sociais da gravidez e as exigências da maternidade, alterando o sentido da imagem corporal e mexendo com a sua aparência física tão valorizada nesta fase (ALMEIDA, 2003). Deste modo, a adolescente acaba por ser de certa forma uma criança que vai entrar de maneira abrupta no mundo adulto, ela que ainda recebe cuidados vai passar a prestar esses cuidados (MENDES et al., 2011; ROQUE, 2003).

Em Portugal, os Centros de Apoio à Vida (CAV) são uma resposta social dirigida ao apoio e acompanhamento de adolescentes e jovens grávidas ou puérperas com filhos/as recém-nascidos, que se encontrem em risco emocional ou social. Esta instituição surge enquadrada na proteção à família preconizada na Lei de Bases do Sistema da Segurança Social, Decreto Lei no 32/2002, de 20 de dezembro, que prevê no seu artigo $85^{\circ}, n^{\circ} 3$, a criação do CAV que visa proporcionar condiçóes de apoio e acompanhamento a essas mulheres.

O CAV onde se desenvolveu a presente investigação visa apoiar e acompanhar adolescentes e/ou jovens grávidas, ou mães com filhos/as, em risco emocional ou social, promovendo a sua (re)integração. Acolhe adolescentes/ jovens grávidas ou com filhos/as até aos três anos de idade. A idade limite das adolescentes/jovens para admissão no CAV é de vinte e um anos (Regulamento Interno do CAV). Neste contexto, este artigo apresenta e discute os resultados de um projeto educativo orientado para a ação de máes adolescentes institucionalizadas num CAV no norte de Portugal, na promoção da sua saúde sexual.

\section{Referencial teórico}

A adolescência é um crescer para a maturidade humana que corresponde a um período de desenvolvimento onde não se é criança nem se é adulto/a, configurando-se como um mundo entre dois mundos (CARVALHO, 2012; TAVARES; ALARCÃO, 2005). Nesta fase, a imagem corporal é muito valorizada e marcada pela preocupação com o peso, o aspeto e as caraterísticas faciais (BRACONNIER, 2002; FONSECA, 2005; PAPALIA; OLDS; FELDMAN, 2004). Surge também o despertar da maturidade sexual, caracterizada por ser um processo biológico mas ao mesmo tempo marcado pela cultura (PAPALIA; OLDS; FELDMAN, 2004), evidenciando que os corpos, as sexualidades e os gêneros são continuamente (re)feitos no dia a dia, desde que nascemos até que morremos, nas interaçóes entre o corpo biológico e as relaçóes de poder, as manifestaçóes de afeto ou violência e a desigualdade material existente nas práticas socioculturais que vivenciamos e que originam 
múltiplos corpos, sexualidades, masculinidades e feminilidades (VILAÇA, 2014). A adolescente tem uma necessidade muito grande de experimentar e viver novas aventuras, não refletindo sobre as consequências dos seus atos, estando aqui presentes a irreverência, transgressáo e o risco associados ao comportamento das adolescentes (CARVALHO, 2012). Assim, nesta fase do ciclo de vida, assume grande importância a contracepção, a prevenção de doenças sexualmente transmissíveis e a prevenção da gravidez, pois é preciso ajudar os/as adolescentes a desenvolver a sua competência para tomarem decisóes, lidarem com as emoçóes e lidarem com os pares e os/as adultos/as, sendo fulcral o estabelecimento de comunicação e o apoio de todos/as aqueles/as que convivem com os/as adolescentes, desempenhando a família ou instituições, no caso das adolescentes institucionalizadas, uma papel preponderante. Segundo o estudo de Carvalho (2012) sobre a experiência da gravidez na adolescência, os comportamentos de risco não estão associados à falta de informação mas sim à busca de prazer e de desejo, náo prevendo as consequências dos seus atos que podem levar à gravidez náo desejada ou às doenças sexualmente transmissíveis. As investigaçôes de Almeida (2003) mostram que a gravidez na adolescência não resulta somente da falência dos métodos contraceptivos mas sim da falência do sistema cultural. Ressalta-se, deste modo, o comportamento inconsistente e revelador de pouca responsabilidade dos/as adolescentes e a falta de conhecimento sobre o seu corpo e a sexualidade. $\mathrm{O}$ medo surge após o ato mas não afeta a decisão de repetir um comportamento de risco (CARVALHO, 2012) pois, como explica Strecht (2011), existe um desfasamento entre o afeto e a sexualidade, denotando-se que as relações sexuais são iniciadas cada vez mais cedo não havendo maturidade emocional necessária para lidar com essas experiências.

Deste modo, analisar a maternidade na adolescência requer uma visão ecológica e sistémica, na medida em que permite analisar os diferentes processos que influenciam o comportamento paternal e maternal, a criança e as ligaçóes que ocorrem entre pais, mães, filhos/as e o seu contexto. A maternidade sofre as influências recíprocas da história desenvolvimental da jovem mãe e das caraterísticas da criança e do contexto no qual se desenvolve essa relaçáo (PORTUGAL, 1998). Não há situaçôes simplistas mas sim, sistemas que se influenciam e que são influenciados pelas pessoas e pelos diferentes meios sociais (PEREIRA, 2002).

É importante estar atento à gravidez na adolescência e sobretudo à repetição deste fenómeno, pois nem sempre é um evento único já que em algumas adolescentes se repete (GODINHO et al., 2000). Tal como refere Strecht (2005), ser pai e mãe implica maturidade emocional e estabilidade sociofamiliar, que é muito difícil ser atingida nesta fase da vida humana; ser mãe adolescente é uma tarefa difícil e a ocorrência de uma segunda gravidez torna essa situação 
muito mais complexa, sendo crucial promover uma maternidade positiva e consciencializar as adolescentes para evitar a reincidência da gravidez. Como vem sendo evidenciado, a maternidade precoce acarreta inúmeros riscos tanto para as adolescentes como para os bebés, sendo que esses riscos são agravados pela repetição de gravidez, constituindo-se, deste modo, como problema de saúde pública (FERREIRA et al., 2012). Neste contexto, é importante promover uma prática educativa que, por um lado, desenvolva nas adolescentes competências para refletirem sobre a sexualidade enquanto um processo que está inerente à maternidade e, assim, evitar a repetição de outras gravidezes não planeadas que acarretará mais responsabilidades para estas adolescentes e levará à acentuação da crise de adolescer e ser mãe. Por outro lado, é importante aumentar o seu conhecimento sobre a prevenção de gravidezes não planeadas e das doenças sexualmente transmissíveis, bem como promover competências de comunicação para saberem comunicar e expressar a sua opinião assertivamente. Para Jardim e Pereira (2006), desenvolver a assertividade permite que as adolescentes sejam capazes de afirmar a sua autonomia, se sintam bem consigo próprias, consigam a sua interdependência, experienciem relaçóes sociais gratificantes, tornem-se profissionais competentes e tenham a capacidade de melhorar a sua maneira de ser e estar face aos novos contextos e circunstâncias.

\section{Metodologia}

\section{i) Descrição geral do estudo}

Este estudo é de natureza qualitativa na medida em que se procura conhecer a experiência das adolescentes respeitando a forma como vivenciam e interpretam a vivência da gravidez e da maternidade. Dentro dos desenhos de investigação qualitativa, optou-se pelo estudo de caso assente numa abordagem metodológica de aproximação à investigação-ação. Tomou-se esta opção porque o que se pretende é a observação de fenómenos ricos e importantes ao nível da informação contida (ALMEIDA; FREIRE, 2007) no desenvolvimento do projeto educativo, que se foca num modelo de análise intensiva das diferentes situaçóes (CUNHA, 2009) que foram surgindo. Esta abordagem conjuga-se com a investigaçãoação, pois procurou-se conhecer a realidade, descobrir conhecimento, mas também promover a mudança mediante a participaçáo constante da população investigada, possibilitando que a "prática e teoria encontrem um espaço de diálogo” (CUNHA, 2009, p.82) que leva às mudanças positivas desejadas.

Ao nível da recolha de dados, para avaliar as necessidades de formaçáo em educação em sexualidade das mães adolescentes, foi utilizada a técnica de desenho-história (RODRIGUES et al., 2010). Primeiro, solicitou-se às jovens que fizessem um desenho sobre a sua gravidez, disponibilizando-se o material 
necessário para esse efeito (lápis de cor, folha, borracha e lápis de desenho). Num segundo momento, após terminarem o desenho, realizou-se a entrevista para o explorar, que foi gravada com o consentimento informado das jovens. Nas sessóes do projeto educativo foi utilizada a observação participante com elaboração de um diário de bordo onde se registaram todos os contextos, comportamentos e percepçóes sobre os sentimentos das participantes e da formadora, bem como uma reflexão sobre a ação e sugestóes de melhoria do processo educativo para o futuro. No final do projeto foi realizada uma entrevista semiestruturada que visou complementar os dados recolhidos nas sessôes e conhecer a opinião das adolescentes sobre a aplicabilidade e o impacto do projeto educativo nas suas vidas. Todos os dados foram transcritos e analisou-se o que aconteceu com cada uma das adolescentes mães durante o projeto, sem fragmentar a realidade e sem a descontextualizar, partindo dos próprios dados (métodos indutivos), e não de teorias prévias, para os compreender ou explicar, situando-se mais nas peculiaridades do que na obtenção de leis gerais (ALMEIDA; FREIRE, 2007).

\section{ii) Metodologia do projeto educativo}

O projeto educativo, denominado "Crescer Saudável", foi estruturado em função dos dados recolhidos na primeira entrevista e na atividade inicial de brainstorming.

Este projeto foi organizado em quatro sessóes com a duração de cerca de uma hora para cada sessão, com os objetivos e estratégias descritas no quadro 1. 
Quadro 1 - Objetivos e estratégias do projeto educativo

\begin{tabular}{|c|c|c|c|}
\hline $\begin{array}{l}\text { NÚMERO } \\
\text { SESSÃO }\end{array}$ & TEMA & OBJETIVOS & ESTRATÉGIAS \\
\hline 1 & Brainstorming & $\begin{array}{l}\text { - Conhecer o interesse das ado- } \\
\text { lescentes } \\
\text { - Promover a participação ativa } \\
\text { das adolescentes }\end{array}$ & $\begin{array}{l}\text { - Nuvem de problemas e priori- } \\
\text { zação dos problemas } \\
\text { - "Desenho da árvore” (Apên- } \\
\text { dice 1) }\end{array}$ \\
\hline 2 & $\begin{array}{l}\text { Saúde Sexual } \\
\text { e Reprodutiva }\end{array}$ & $\begin{array}{l}\text { - Promover a utilizaçáo cons- } \\
\text { ciente da contracepção }\end{array}$ & $\begin{array}{l}\text { - Vídeo "Seis histórias e de- } \\
\text { pois?" cena } 3 \text { "mais fácil como?" } \\
\text { da Associação para o Planea- } \\
\text { mento Familiar (APF) } \\
\text { - Análise do filme: debate } \\
\text { - Distribuição da Brochura } \\
\text { "Métodos Contraceptivos: uma } \\
\text { escolha tua" da APF } \\
\text {-Resumo da Sessão: Panfleto } 1 \\
\text { (Apêndice 2) }\end{array}$ \\
\hline 3 & $\begin{array}{l}\text { Saúde Sexual } \\
\text { e Reprodutiva }\end{array}$ & $\begin{array}{l}\text { - Promover a prevenção das } \\
\text { DST's }\end{array}$ & $\begin{array}{l}\text { - PowerPoint sobre as DST's } \\
\text { - Debate } \\
\text { - Panfleto 2: DST's } \\
\text { - Resumo da Sessão: Cartaz } 1 \\
\text { * Sessão com a colaboração } \\
\text { de uma das adolescentes que } \\
\text { participa no programa cujo } \\
\text { tema da sua Prova de Aptidão } \\
\text { Profissional são as DST's }\end{array}$ \\
\hline 4 & $\begin{array}{l}\text { Prevenção da } \\
\text { Repetição da } \\
\text { Gravidez }\end{array}$ & $\begin{array}{l}\text { - Promover a prevenir uma } \\
\text { segunda gravidez } \\
\text { - Consciencializar para a } \\
\text { importância da continuidade } \\
\text { dos estudos } \\
\text { - Encorajar a planear a carreira }\end{array}$ & $\begin{array}{l}\text { - "Batata quente" } \\
\text { - Debate sobre a maternidade e } \\
\text { suas consequências } \\
\text { - Definição de objetivos } \\
\text { pessoais } \\
\text { - Resumo da Sessão: Panfleto } 2\end{array}$ \\
\hline
\end{tabular}

Fonte: Elaboração própria.

As sessões foram desenvolvidas de forma dinâmica e interativa e o horário de cada sessão foi previamente marcado com as adolescentes atendendo à sua disponibilidade, daí terem sido realizadas mais do que uma sessão por cada tema pela impossibilidade de as reunir todas numa mesma sessão.

Para as sessões foram construídos e utilizados materiais didáticos como jogos, atividades e panfletos, sendo estes submetidos à apreciação de uma especialista da área da saúde materno infantil e de outra especialista em educação para a saúde. Antes de terminar cada sessão procedeu-se ao resumo da mesma, 
sendo a informação registada em panfletos e cartazes. Após terminar as sessões, a investigadora procedeu ao registo de cada sessão.

\section{Participantes}

Neste artigo serão referidos os casos de três das cinco adolescentes que se encontravam institucionalizadas num CAV no norte de Portugal onde a investigadora trabalhava, e que fizeram parte deste estudo. As máes adolescentes tinham entre 19 e 22 anos e eram todas solteiras. Em relação ao nível de escolaridade, uma tinha o $9^{\circ}$ ano, uma o $6^{\circ}$ ano de escolaridade e outra no $12^{\circ}$ ano (Tabela 1).

Tabela 1 - Caraterização das adolescentes mães

\begin{tabular}{|c|c|c|c|c|c|c|c|c|}
\hline \multirow[t]{2}{*}{$\begin{array}{c}\text { NOME } \\
\text { SIMULADO }\end{array}$} & \multirow[t]{2}{*}{ IDADE } & \multirow[t]{2}{*}{$\begin{array}{l}\text { NÍVEL } \\
\text { ESCOLAR }\end{array}$} & \multirow[t]{2}{*}{ PROFISSÃO } & \multirow{2}{*}{$\begin{array}{l}\text { IDADE } \\
\text { DO } \\
\text { BEBÉ }\end{array}$} & \multicolumn{2}{|c|}{$\begin{array}{l}\text { NÍVEL ESCOLAR } \\
\text { DOS PAIS DAS } \\
\text { ADOLESCENTES }\end{array}$} & \multicolumn{2}{|c|}{$\begin{array}{l}\text { PROFISSÁO DOS PAIS } \\
\text { DAS ADOLESCENTES }\end{array}$} \\
\hline & & & & & PAI & MÄE & PAI & MÁE \\
\hline Gabriela & 19 & $6^{\circ}$ ano & Estudante & $15 \mathrm{~m}$ & $4^{\circ}$ ano & $6^{\circ}$ ano & Marceneiro & Doméstica \\
\hline Maria & 22 & $12^{\circ}$ ano & Estudante & $3 a$ & $4^{\circ}$ ano & $9^{\circ}$ ano & Trolha & Emp. fábrica \\
\hline Filipa & 20 & $9^{\circ}$ ano & Estudante & $2 \mathrm{a}$ & \multicolumn{2}{|c|}{ Já faleceram } & \multicolumn{2}{|c|}{ Faleceram } \\
\hline
\end{tabular}

Fonte: Elaboração própria.

Exceto uma das mães adolescentes, todas tinham ficado retidas durante a sua escolaridade. As três mães adolescentes estudavam, tendo os seus bebés idades entre os 15 meses e os três anos. A mãe e o pai das mães adolescentes têm baixas qualificaçôes.

\section{Apresentação e discussão dos resultados}

\section{i) Vivência da gravidez}

Caso da Gabriela. A Gabriela é uma adolescente com 19 anos e mãe de uma menina de 15 meses. É solteira e não exerce nenhuma profissão. Antes de residir na instituição a Gabriela vivia com o padrasto e a mãe. O pai do seu filho tem 38 anos, tem o $6^{\circ}$ ano de escolaridade e atualmente não trabalha. Este relacionamento entre a Gabriela e o pai do seu filho já terminou pois, tal como afirmou, "já não gosto dele". A Gabriela optou por desenhar o princípio da gravidez porque "se não, tinha que me pôr muito inchada" (Figura 1). 
Figura 1 - Desenho da Gabriela sobre a sua gravidez

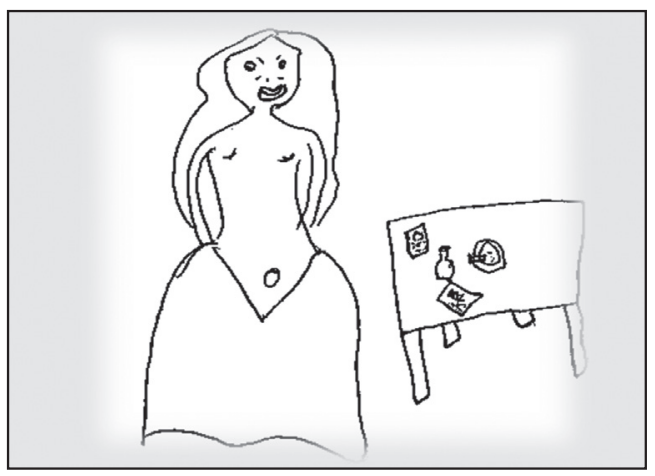

Fonte: Elaboração própria.

A Gabriela desenhou o corpo pormenorizadamente da cintura para cima, revelando a parte do corpo que mais alteração sofreu com a gravidez. Contextualiza o desenho no espaço através da mesinha com os seus pertences.

A gravidez da Gabriela decorreu normalmente. Considerou que não alterou nada por estar grávida. Revelou que durante a gravidez o mais importante era "que a minha filha nascesse bem". Nesta fase de vida sentiu-se mais calma, considerando que o seu corpo "não mudou muito" e apenas vomitou no início da gravidez. Relativamente a si própria sentiu que "não tinha que me preocupar com nada", não tinha medo de nada já que "esta menina era desejada". Face à bebé, referiu que se emocionou quando ouviu o seu coração, referindo: "fiquei feliz mas assustei-me". Durante a gravidez a Gabriela foi regularmente ao médico.

O pai da sua filha reagiu bem à gravidez, pois também queria a filha. Com a gravidez deixou de ter relaçóes sexuais e depois continuou sem as ter, pois entrou para o CAV. Relativamente, à sua vida amorosa no futuro revelou: "não me quero relacionar com mais ninguém". Para a Gabriela a prevenção da gravidez cabe à mulher, "os homens lá querem saber dos filhos", por sua vez, a prevenção das DST's cabe ao homem e à mulher, considerando que a sua prevenção passa por se "lavar bem lavadinha, ter cuidado, não ter relaçóes com qualquer um".

Face a si, a Gabriela acreditava nas suas capacidades, dizendo: "o que eu quero consigo". Face ao seu corpo revelou que os cuidados que tinha eram ao nível da higiene, pois com a alimentação não tinha preocupaçôes, dizendo: "não engordo e não, posso comer bem".

Caso da Maria. A Maria é uma adolescente com 22 anos e mãe de uma menina de três anos. É solteira e está a acabar o $12^{\circ}$ ano. Antes de residir no 
CAV, a Maria vivia com o pai da sua filha. O pai da sua filha tem 24 anos, tem o $6^{\circ}$ ano de escolaridade e atualmente náo trabalha. Este relacionamento entre a Maria e o pai da sua filha já terminou, pois: "quando vim para aqui deixou de querer saber da menina e automaticamente deixou de falar comigo". A Maria desenhou o $5^{\circ}$ mês de gestação, retratando a fase mais complicada da gravidez devido às discussóes com o pai da sua filha (Figura 2).

Figura 2 - Desenho da Maria sobre a sua gravidez

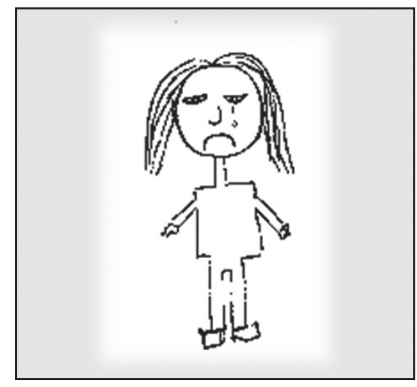

Fonte: Elaboração própria.

Usou traços retos para se desenhar, optando por desenhar o corpo completo mostrando no rosto desenhado infelicidade e desanimo. Com o desenho pretendeu mostrar que estava infeliz: "apesar de estar feliz por estar grávida [...] estava infeliz porque não era o que tinha idealizado". Revelou que o início da gravidez "foi muito bom", mas depois "as coisas pioraram porque ele começou a sair, começou a não ter paciência para mim e aí começaram as discussóes, a bater".

Durante a gravidez a Maria referiu que "mudou o meu comportamento, a minha atitude como pessoa, tudo". Recordou como mais positivo "as conversas que tinha para dentro da barriga", pois "era a única pessoa com quem podia falar". De mais negativo, recordou "a parte de não ter compreensão por parte de ninguém". Ao longo da gravidez revelou que o seu corpo mudou, no entanto, "nem ligava a essa mudança, estava tão preocupada com o que se passava fora dessa mudança...". Mencionou que a anca foi o que mais mudou e que isso teve impacto na sua vida, já que "não estava habituada".

Em relação a si pensava: "como é que seria depois da criança nascer... ia ficar sozinha". Teve medo "de perder a minha filha", porque "com as discussóes que havia em casa a Comissão [Comissão de Proteção de Crianças e Jovens] foi alertada”. Relativamente à bebé, revelou emoção quando ouviu pela primeira vez o coraçấo da sua filha e sentiu os primeiros pontapés: "o crescimento dela era bom era positivo". 
Durante a gravidez teve um bom acompanhamento médico: "fui acompanhada desde as 7 semanas". Revelou que o único problema que teve foi: "o início de um descolamento da placenta”, devido a uma agressão do companheiro.

Tratou-se de uma gravidez náo planejada, resultado de um "clima alto" depois da saída de uma discoteca. Considerou que para não engravidar não deveria ter tido relaçóes embriagada e devia ter usado contracepção. Conhecia a pílula do dia seguinte mas não usou porque "não sabia se poderia acontecer alguma coisa" e "supostamente não estava no período fértil". Para prevenir a gravidez considerou que deve usar-se contracepção: "pílula... preservativo... outros contraceptivos". No futuro pensa usar "todos os métodos contraceptivos necessários".

Quando descobriu que ficou grávida a sua reação "não foi má mas também não foi boa", pois interrompeu a vida militar. A "parte positiva foi que iria ter alguém igual a mim ou pelo menos parecida comigo". Contou ao pai da filha e ele reagiu bem, mas "a partir dos cinco meses é que começou o desastre". Na altura que contou ao pai da sua filha sentiu que "ele estava feliz". Também contou à sua família que ficou reticente. Optou por seguir com a gravidez porque é contra o aborto e "tinha esperança naquela criança, esperança que me mudasse". Nunca pensou dar a sua filha para adoção porque "é minha".

Durante a gravidez mudou o seu desejo sexual e afirmou que: "muitas vezes fui forçada a faze-lo [a ter relaçóes sexuais]". Depois da gravidez: "não conseguia ter relacionamento com nenhum rapaz”. Face ao futuro, não revelou preocupação com a sua vida sexual e amorosa. Para a Maria, a prevenção da gravidez e das DST's cabe ao homem e à mulher. No futuro pensa prevenir as DST's usando métodos preventivos. Embora esta seja uma resposta muito geral, por todo o discurso da Maria e atendendo à sua participação no projeto denotouse conhecimentos relativos à prevenção das DST's e da gravidez.

Sobre si, a Maria pensa que "é um exemplo para muitas raparigas, porque luto por aquilo que quero e tenho ambição na vida e luto pela minha filha". Com a alimentação tem poucos cuidados e com o seu corpo "não sou muito de ligar a dietas ou ficar perfeita, porque ninguém é perfeito".

Caso da Filipa. A Filipa é uma adolescente com 20 anos e mãe de um menino com dois anos. É solteira, tem o $9^{\circ}$ ano de escolaridade e é estudante. Antes de residir no CAV, a Filipa vivia com o pai do seu filho, a mãe e um irmão deste. $\mathrm{O}$ pai do seu filho tem 23 anos e não trabalha. Este relacionamento amoroso entre a Filipa e o pai do seu filho já terminou pois "não nos damos bem". Quando se pediu à Filipa para se desenhar durante a gravidez, fez o desenho da figura 3. 
Figura 3 - Desenho da Filipa sobre a sua gravidez

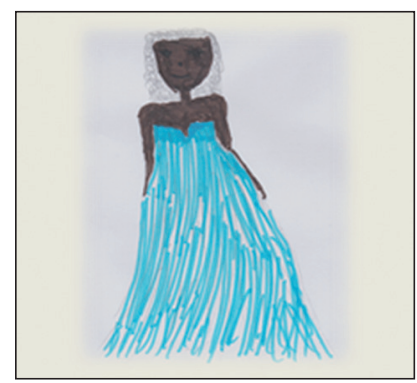

Fonte: Elaboração própria.

A Filipa desenhou o $5^{\circ}$ mês de gestação, porque foi a fase em que se sentiu mais bonita "com aquele barrigona". Com este desenho pretendeu mostrar que "às vezes há uma fase em que nós ficamos mais bonitas". Considerou que com a gravidez o seu corpo mudou ao nível dos seios e a sua principal preocupação era o "medo de perder a barriga bonita". Não foi uma gravidez planeada, mas confessou que às vezes pensava que tinha sido planeada, porque "queria muito ter um filho". Para a Filipa a prevenção da gravidez e das DST's cabe ao homem e à mulher.

Revelou que a sua gravidez acabou por ser um pouco stressante já que "tava na casa deles, depois vim parar a um colégio", no entanto, "foi, é incrível". Com a gravidez, "não modificou nada", mas acabou por revelar que cresceu "mais ou melhor, fui obrigada a crescer e aprendi muitas coisas como é ser mãe". Recordou que o mais positivo da sua gravidez foi o poder relaxar, "não me preocupava tanto com os outros e tanto com a vida, preocupava-me mais comigo". Como aspeto negativo realçou a falta de apoio do pai do seu filho. Ao longo da gravidez revelou que se tornou mais forte e mais madura. $\mathrm{O}$ impacto destas mudanças na sua vida ia oscilando, pois havia dias "que eu tava sempre a pensar, mas havia outros que nem sequer me importava". Em relação a si, a Filipa "pensava que era uma mulher forte", mas tinha medo que lhe tirassem o filho, "já que tou numa instituição".

O acompanhamento médico da Filipa na gravidez "foi ótimo, segui as consultas normais, não tive nenhum problema de saúde", referindo que teve muitos cuidados para consigo e para com o seu filho, já que "se eu ficar doente ele também fica". Conhece a pílula do dia seguinte e não a usou pois compara-a a um aborto. Afirmou: "Sou contra o aborto" e, por isso, conhecendo a despenalização da interrupção voluntária da gravidez não abortou tendo em conta que também "queria muito ter um filho". A adoção estava fora de questão já que "é meu filho". Considerou que a melhor forma de prevenir uma gravidez é o implanon, sendo este o seu método contraceptivo atual. 
Quando descobriu que estava grávida, a Filipa ficou feliz e em choque "porque não estava à espera", de seguida "gritei de alegria". O pai do seu filho estava presente no momento em que a Filipa soube que estava grávida e "ficou mais branco do que aquilo que é, mas depois também gritou de alegria". Face ao bebé, revelou que o primeiro pontapé "foi uma alegria" e que ao ouvir pela primeira vez o coração do seu filho "fiquei emocionada".

A vida sexual da Filipa não se alterou nem antes nem depois da gravidez. A sua preocupação com a sua vida amorosa e sexual no futuro passa "por náo cometer o mesmo erro". Para ela, a responsabilidade de prevenir a gravidez e as DST's cabe ao homem e à mulher, porque "tanto eu como ele podemos ter doenças". A proteção contra as DST's passa pelo uso de preservativo.

Face a si, a Filipa afirmou: "consigo tudo o que quero". Quanto à alimentação revelou "abuso um bocadinho, eu gosto de comer" e sobre o seu corpo referiu que tem muitos cuidados para não engordar, embora tendo consciência de que "sou um esqueleto mas eu não quero engordar, ter borbulhas na cara e pronto... o cabelo esse não se pode dizer nada".

\section{ii) Experiências e aprendizagens no projeto educativo}

Caso da Gabriela. A Gabriela manifestou indiferença pela sua participação no projeto, tendo afirmado que foi "normal" e que recomendaria o projeto, "porque são coisas que nem todas as mães sabem". Relativamente às sessôes sobre sexualidade, disse que aprendeu que o mais importante é ter cuidado, sentindo-se mais esclarecida sobre os métodos contraceptivos. No que concerne ao material didático gostou mais dos filmes. Referiu que a sessão sobre as doenças sexualmente transmissíveis contribuiu para mudar o seu comportamento devido à importância da dupla proteção, "usar os dois [uso simultâneo da pílula e do preservativo]", e que a prevenção das DST’s passa pelo uso do preservativo (Entrevista Final), mostrando uma grande evolução no seu conhecimento em relação ao início do projeto, pois nessa altura tinha afirmado que a prevenção de DST's passava por "se lavar bem lavadinha" e "não ter relaçóes com qualquer um".

Caso da Maria. A Maria considerou que a sua participaçáo no projeto foi boa, revelou que o importante foi participar e que "pude ajudar em certos temas, acho que também foi bom para enriquecer o meu pensamento e o meu estudo". Gostou mais das "partes interativas" e da "parte de jogar e, entre aspas, brincar com os temas". Gostou menos da "parte maçuda de estar ali a ouvir". Mudaria a participação de certas colegas, pois considerou que "nós estamos a precisar de ouvir certas reflexóes". Considerou que não era preciso acrescentar mais nenhum tema, no entanto, "acho que deveria desenvolver mais o tema da contracepção ao nível das causas e das consequências". Recomendaria este projeto pois: "poderá 
prevenir para não haver outra criança"; "proteger e promover uma vida sexual [...] ativa e boa com o parceiro".

Relativamente às sessóes sobre a sexualidade, a Maria considerou que "qualquer assunto que venha a favor do nosso desenvolvimento a nível sexual e etc. acho que é bom”, “a comunicação é muito importante, porque assim as mulheres e homens, vá as raparigas e os rapazes, têm sempre oportunidade de poderem, neste caso, precaverem-se". Referiu que a contracepção é o tema mais importante, embora todos os outros também o sejam. Face à contracepção considerou-se mais esclarecida depois do projeto, e defendeu que é importante os pais e educadores falarem sobre este assunto com os filhos. Sobre as DST's considerou-se mais esclarecida, pois referiu que aprendeu sobre as suas caraterísticas e que algumas levam algum tempo a manifestar-se.

A Maria mencionou que "toda a parte prática é boa", desde filmes a PowerPoints com imagens. Gostou menos da "parte de falar", pois considerou que "escrever é mais fácil", embora até goste muito de falar. Na sua opinião não era necessário mais material. Referiu que as sessóes estavam bem organizadas, mas achou que "se todas tivéssemos em conjunto nas sessóes conseguiríamos debater muito melhor". Revelou que aprende melhor com uma colega do que com uma formadora, pois "tá no mesmo mundo que nós e basicamente passa exatamente o que nós passamos".

Face ao futuro, a Maria revelou que a sua vida ideal "era ter uma boa casa, um bom salário para sustentar e dar uma boa vida à minha filha”. Pensa que a sua vida será complicada e para que os seus sonhos se aproximem da realidade referiu que precisa de "trabalhar para alcançar os objetivos". Referiu, também, que se considerava mais esclarecida sobre os métodos contracetivos e sobre as DST's, dizendo: "que apesar de eu já saber que temos de usar a proteção necessária, acho que é sempre bom ouvir mais uma vez". Afirmou que com a formação vai mudar as suas práticas sexuais no futuro, já que aprendeu "que há doenças que se desenvolvem logo na altura [...] e que há DST's que duram dez, quinze, muitos anos a desenvolverem-se".

Caso da Filipa. Para a Filipa a sua participação no projeto foi positiva. Gostou mais da sessão orientada pela colega pois "aprendemos mais". Relativamente ao que gostou menos referiu: "não houve nada que eu não gostasse". No que se refere às atividades, revelou que talvez mudasse alguma coisa, dizendo: "mais práticas, filmes e jogos". Mencionou que os temas tratados são suficientes e recomendaria este projeto a outras adolescentes já que "assim elas tinham mais conhecimentos".

Relativamente à sua vida sexual considerou que continuava tudo normal e que face ao futuro "não tenho problema". Quanto aos métodos contraceptivos explicou que sempre esteve esclarecida, mas que a sessão sobre a contracepção e as DST's mudaram as suas práticas a todos os níveis, especialmente a sua 
assertividade com o futuro companheiro para usarem o preservativo e os cuidados com o uso da contracepção. Face ao material didático, referiu que gostou mais dos filmes porque "chamam mais a atenção" e gostou menos do PowerPoint. Para si, as sessóes estavam bem organizadas e como havia referenciado anteriormente, considerou que aprende melhor com uma colega, porque "estamos mais à vontade". Face à sessão sobre os métodos contraceptivos, a Filipa referiu que sempre esteve esclarecida revelando preocupação com a sua saúde e a do seu parceiro, salientando a importância do acompanhamento médico regular e o uso da contracepção (Diário de Bordo). Na sessão sobre as DST’s foi participando ativamente e levantando questóes relativas ao HPV e outras infeçóes (Diário de Bordo), mencionando na entrevista sobre o projeto educativo que esta sessão contribuiu para a mudança do seu comportamento, na medida em que mudou as suas práticas sexuais a "todos os níveis".

No futuro idealizou viver a maternidade como "sempre sonhei" e gostaria que a sua vida fosse "boa, muito boa", "ter uma grande casarona, ter tudo do melhor para dar ao meu filho". Pensa que vai "ser feliz" e que para atingir isso tem que "trabalhar muito".

\section{Considerações finais}

Nos dois primeiros casos as mães adolescentes escolheram a fase da gravidez que desenharam em função de aspectos negativos que percepcionaram na sua gravidez. A Gabriela optou por fazer um desenho do inicio da gravidez porque "se não tinha que me por muito inchada" e a Maria retratou o $5^{\circ}$ mês de gestação, por ser a fase mais complicada da gravidez devido às discussóes com o pai da sua filha. No terceiro caso, a Filipa optou por desenhar os aspectos positivos da sua gravidez, ilustrando um período da gravidez avançado que coincidiu com o momento em que se sentiu mais bonita e feliz com o facto de estar grávida. Com a gravidez todas estas adolescentes revelaram mudanças sobretudo ao nível da personalidade e do corpo, manifestando, principalmente a Filipa, preocupaçóes com a imagem corporal, muito caraterística da fase da adolescência, como referenciado por inúmeros autores (BRACONNIER, 2002; FONSECA, 2005; PAPALIA; OLDS; FELDEMAN, 2004). No entanto, face a essas mudanças a Maria e a Filipa acabaram por lidar bem com as alteraçóes ocorridas.

O relacionamento amoroso das três mães adolescentes parece ter terminado como consequência da gravidez náo planeada, embora todas conhecessem os métodos contraceptivos, mesmo no primeiro caso em que a adolescente e o pai da criança desejavam ter um filho.. Uma adolescente defendeu que a prevenção da gravidez cabe somente à mulher, embora todas tivessem considerado que a prevenção das DST's é da responsabilidade do homem e à mulher. Estes resultados mostram como é importante educar para a coresponsabilidade do 
par no planeamento familiar e na prevenção de DST's. A gravidez da Maria e Filipa foi o resultado da não utilização ou da utilização inadequada dos meios de contracepção. A Gabriela revelou ter sido uma gravidez não planeada mas desejada. Este facto, vem ao encontro do mencionado por Carvalho (2012), quando referiu que os comportamentos de risco estáo associados ao prazer e, como a Maria revelou, estavam em "clima alto", não equacionando as consequências dos seus atos. A Gabriela revelou alguns mitos em relação à prevenção das DST's, como, por exemplo, "lavar bem lavadinha”, o que revela a importância de desmistificar mitos e trabalhar informação cientificamente válida sobre as DST's, como nos é referenciado por Santos, Ogando e Camargo (2001).

Relativamente à autoestima e autoconfiança, todas estas adolescentes revelaram evidências de boa autoestima e autoconfiança. Por exemplo, afirmaram que gostam de si, que lutam pelo que querem, como a Maria, a Filipa e a Gabriela, e que têm ambição, como a Maria, revelando capacidades resilientes e de luta pelos seus objetivos.

Relativamente à evolução dos conhecimentos e das práticas durante o desenvolvimento do projeto educativo, as três adolescentes revelaram que se sentiam mais esclarecidas sobre as DSTs e a prevenção da gravidez e que as sessôes terão impacto nas suas práticas sexuais, com exceção de uma adolescente para a qual não houve qualquer impacto. Face ao projeto educativo duas das adolescentes gostaram de participar e têm uma visão positiva do projeto. Uma adolescente revelou indiferença pela sua participação. Todas as adolescentes consideraram que os temas tratados no projeto foram os adequados, o material didático preferido foi o vídeo, e do que gostaram menos foram os jogos e a parte das sessōes em que era utilizado o PowerPoint. Duas adolescentes valorizaram a educação pelos pares em detrimento da formação realizada pela formadora/ investigadora.

Face ao futuro, estas adolescentes revelaram formas diferentes de viver a maternidade consoante os seus sonhos e o modo que a vivem atualmente, e acreditam que será melhor vivida no futuro por causa das aprendizagens que adquiriram especialmente com a sua história de vida, embora o projeto educativo também vá contribuir para isso. Face ao futuro, para todas estas adolescentes ter um emprego e ter o apoio para criar o filho ou filha está na base da concretização dos seus sonhos, refletindo a importância do apoio de familiares e amigos e da influência destes na sua vida, tal como já referido noutras investigaçóes (BRONFENBRENNER, 1996, 2005; PAYNE, 2002; PEREIRA, 2002).

Perante estas conclusóes pode inferir-se que é importante desenvolver projetos educativos orientados para a ação na promoção da maternidade saudável com adolescentes institucionalizadas para promover a saúde sexual das mães adolescentes e a igualdade de género. 


\section{REFERÊNCIAS}

ABUCKAIM, E. S. V. Vivenciando a amamentaçáo e a sexualidade na maternidade: dividindo-se entre ser mãe e mulher. 2005. 191 f. Tese (Doutodo em Enfermagem) Universidade de São Paulo, São Paulo, 2005.

ALMEIDA, J. M. Adolescência e maternidade. 3.ed. Lisboa: Calouste Gulbenkian, 2003.

ALMEIDA, L. S.; FREIRE, T. Metodologia da investigaçáo em psicologia e educaçáo. 4.ed. Braga: Psiquilíbrios, 2007.

BRACONNIER, A. O guia da adolescência. Lisboa: Prefácio Edições, 2002. v.1.

BRONFENBRENNER, U. Making human beings human. Califórnia: Sage, 2005.

. A ecologia do desenvolvimento humano: experimentos naturais e planejados. Porto Alegre: Artes Médicas, 1996.

CANAVARRO, M. C. Psicologia da gravidez e da maternidade. Coimbra: Quarteto, 2001.

CARVALHO, D. Aquela pequena vírgula é meu filho!: a experiência da gravidez na adolescência. Coimbra: Ediçóes Humus, 2012.

CUNHA, M. J. Investigaçáo científica: os passos da pesquisa científica no âmbito das ciências sociais e humanas. Lisboa: Ousadias, 2009.

FERREIRA, C. L. et al. Repetição de gravidez na adolescência: estudos sobre a prática contraceptiva em adolescentes. Revista Estudos e Pesquisas em Psicologia, Rio de Janeiro, v.12, n. 1, p.188-204, 2012.

FONSECA, H. Viver com Adolescentes. 3.ed. Lisboa: Editorial Presença, 2005.

GODINHO, R. A. et al. Adolescentes e grávidas: onde buscam apoio? Revista LatinoAmericana de Enfermagem, Ribeirão Preto, v. 8, n. 2, p.25-32, 2000.

JARDIM, J.; PEREIRA, A. Competências pessoais e sociais. Porto: Ediçôes Asa, 2006.

MENDES, T. et al. Mães adolescentes: adaptação aos múltiplos papéis e a importância da vinculação. Psicologia: Reflexão e Crítica, Porto Alegre, v. 24, n. 2, p. 309-317, 2011.

MONTEIRO, R. O que dizem as mães. Lisboa: Quarteto, 2005.

MOTA, M. D. B.; MADEIRA, M. Z. A. Feminino e feminicídio. Fortaleza: Expressão Gráfica Editora, 2010.

PAPALIA, D. E.; OLDS, S. W.; FELDEMAN, R. D. O mundo da criança. 8.ed. Lisboa: McGraw-Hill, 2004.

PAYNE, M. Teoria do trabalho social moderno. Coimbra: Quarteto, 2002.

PEREIRA, A. P. S. Análise das condiçôes de risco numa perspectiva ecológica. InclusãoRevista de Educaçáo Especial, Brasília, v. 2, p. 75-90, 2002.

PORTUGAL, G. Crianças, famílias e creches: uma abordagem ecológica da adaptação do bebé à creche. Porto: Porto Editora, 1998. 
RODRIGUES, D. P. et al. Ser mãe adolescente: representaçóes de puérperas adolescentes a partir da técnica do desenho-estória. Reme: Revista Mineira de Enfermagem, Belo Horizonte, v. 14, n.3, p. 308-315, 2010.

ROQUE, O. Mamãs de palmo e meio: gravidez e maternidade adolescentes. Lisboa: Associação para o Planeamento da Família, 2003.

SANTOS, A. C.; OGANDO, C.; CAMACHO, H. Educaçáo da sexualidade na escolar: da teoria à prática. Lisboa: Didáctica, 2001.

STRECHT, P. O vento à volta de tudo. Lisboa: Verso de Kapa, 2011.

. Vontade de ser: textos sobre adolescência. Lisboa: Assírio \& Alvim, 2005.

TAVARES, J.; ALARCÁO, I. Psicologia do desenvolvimento e da aprendizagem. 7.ed. Coimbra: Almedina, 2005.

VILAÇA, T. Percepçóes de professores/as sobre as diferenças de género na educação em sexualidade em escolas portuguesas. Educação: Teoria e Prática, Rio Claro, v. 24, n.45, p.23-39, 2014.

VILAR, D.; GASPAR, A. M. Traços redondos. In: PAIS J. M. (Org.). Traços e riscos de vida. 3.ed. Lisboa: Ambar, 2005. p.27-75. 


\section{Resumo}

\section{Educação em sexualidade de mães adolescentes institucionalizadas num centro de apoio à vida}

A investigação sobre a maternidade na adolescência tem vindo a mostrar os efeitos negativos que ela provoca na sexualidade da mãe adolescente e nos diversos níveis da sua trajetória desenvolvimental, particularmente nos domínios educacional, socioeconómico, ocupacional, social e psicológico. Neste sentido, esta investigação tem como objetivo caraterizar os efeitos de um projeto educativo que visa desenvolver a competência de máes adolescentes, institucionalizadas num Centro de Apoio à Vida em Portugal, para promoverem a sua saúde sexual. Foram envolvidas no projeto cinco mães adolescentes e, neste artigo, serão apresentados os casos de três dessas mães. Os dados recolhidos através de uma entrevista individual anónima no início e no fim do projeto, por observação participante e por análise dos documentos produzidos pelas adolescentes durante o projeto educativo, foram triangulados. Ao longo do projeto verificou-se que estas mães adolescentes melhoraram os seus conhecimentos sobre o evitamento da reincidência da gravidez e das doenças sexualmente transmissíveis, e mostraram algumas evidencias de que aumentaram a sua autoestima e assertividade em relação ao seu parceiro sexual. Estes resultados mostram que os projetos educativos orientados para a açáo na promoção de sexualidades saudáveis em mães adolescentes institucionalizadas poderáo ser uma mais valia para promover a sua saúde sexual e alcançar a igualdade de género.

Palavras-chave: Maternidade na adolescência. Educação em sexualidade. Competência para ação. Portugal.

\section{Abstract}

\section{Sexuality education of adolecent mothers institutionalized in a life support centre}

Research on motherhood during adolescence has been showing the negative effects that it causes in the adolescent mother's sexuality and in the various levels of her developmental trajectory, particularly in the educational, socio-economic, occupational, social and psychological fields. Therefore, this research aims to characterize the effects of an educational project aimed at developing the ability of adolescent mothers, institutionalized in a Support Centre for Life in Portugal, to promote their sexual health. Five teenage mothers were involved in the project and, in this paper the cases of three of these mothers will be presented. Data collected through anonymous individual interviews at the beginning and end of the project, participant observation and the analysis of documents produced by adolescents during the educational project were triangulated. Throughout the project it was found that these teenage mothers improved their knowledge about the avoidance of recurrence of pregnancy and sexually transmitted diseases and, shown some evidences that they increased their self-esteem and assertiveness in relation to their sexual partner. These results show that educational action-oriented projects on sexuality health promotion in institutionalized adolescent mothers can be an asset to promote their sexual health and achieve gender equality.

Keywords: Adolescent motherhood. Sexuality education. Action competence. Portugal. 


\section{Apêndice 1 - Desenho da árvore: Brainstorming}

Objetivos

- Refletir sobre as situaçóes adversas da vida.

- Compreender que é possível fazer frente às situaçôes adversas da vida através de um olhar otimista sobre os problemas identificando as suas capacidades.

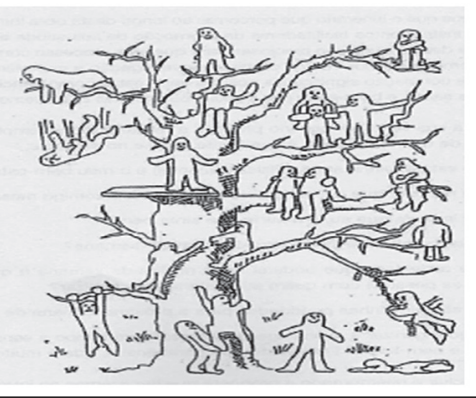

Fonte: Jardim e Pereira (2006, p.180).

\section{Estratégia}

1. Pedir às adolescentes que observem o desenho da Árvore da Escalada da Vida (figura acima) que lhes foi distribuído e assinalem com um círculo a situação que melhor a descreve neste momento.

2. Dizer às adolescentes que assinalem, no desenho, a situação que melhor representa para onde quer ir no futuro próximo.

3. Pedir que olhem atentamente para o desenho e dizerem o que veem (há uns que caem, outros que se levantam, outros que estão presos por um fio).

4. Discutir com as adolescentes o significado do que veem no desenho (perante uma situação adversa há pessoas que apesar de cair se levantam e retomam a sua viagem, outras agarram-se a pequenos suportes que os mantém vivos)

5. Perguntar às adolescentes: "Em relação a ti, como está a tua escalada da vida?"

6. Discutir com as adolescentes os objetivos desta atividade (Esta atividade permite ver que ao longo do percurso da vida vamos encontrando obstáculos de diferentes dificuldades sentindo-nos, por vezes, sem força para continuar. Estando nesta situação devemos usar o otimismo para sair da situação. Sempre que te sentires que não és competente ou eficaz, pára e faz uma "radiografia mental" sobre as tuas competências, identificando aquelas que precisas aperfeiçoar ou tomar decisóes para mudar.) 


\section{Apêndice 2 - Promover a utilização consciente da contracepção}

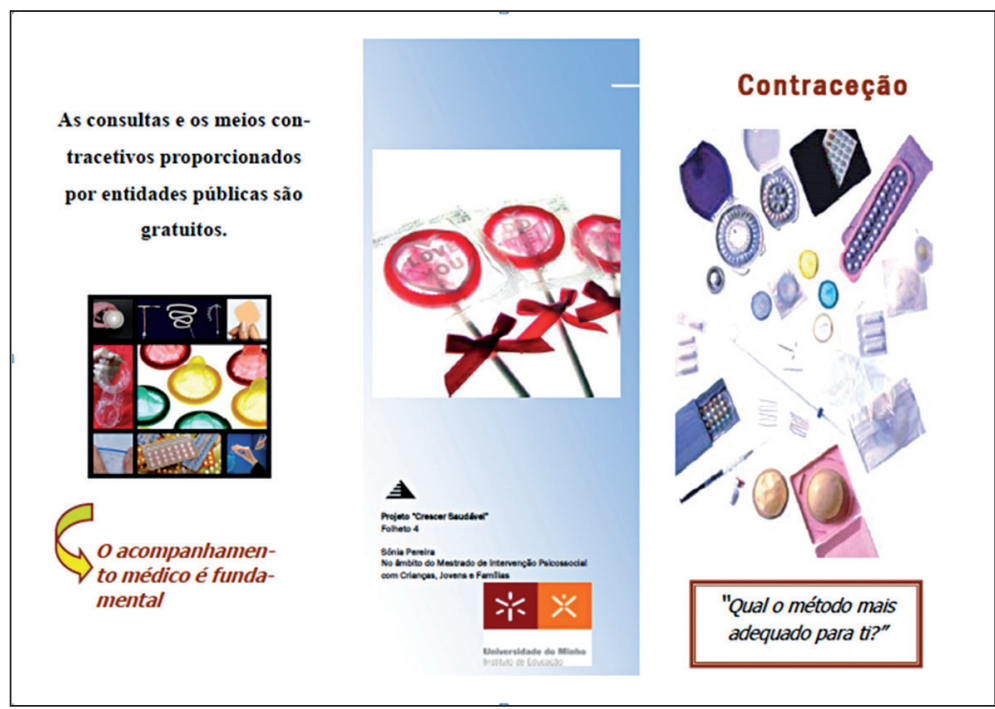

Como escolher o método mais adequado

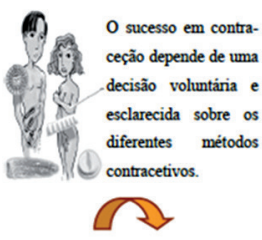

Questões que devem ser colocadas quando se pretende escolher um método contracetivo:

- É o mais conveniente e eficaz? - Está adequado ao meu estilo de vida?

- É reversivel?

-É um método acessivel ?
$\overrightarrow{\mathrm{E}}$ importante praticar seso seguro

¿

Sexo (mais) seguro é sexo com proteção, usando métodos para prevenir uma gravidez indesejada e pana proteger as infecōes sexualmente transmissiveis

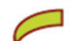

A forma de fazer sexo mais seguro é

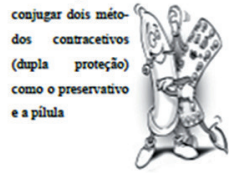

O Planeamento Familiar é um direito

$\sqrt{2}$

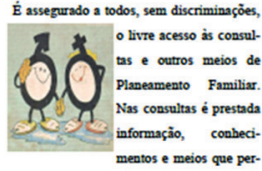

mitem tomar decisões livres e responsi.

veis.

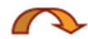

Os jovens podem ser atendidos em qualquer consulta de Planeamento Familiar em centros de savide ou serviços bospitalares pertencentes ou não à sua area residència 